
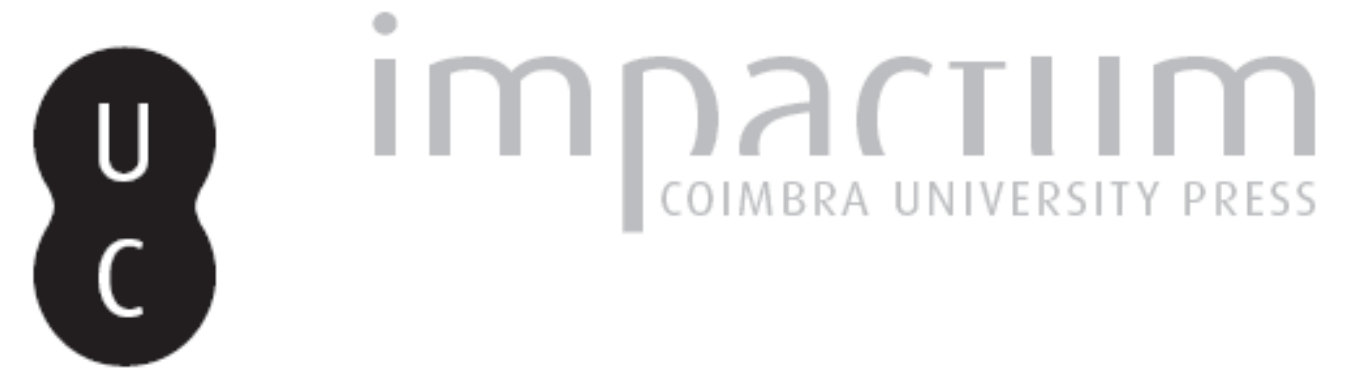

\title{
As artes do Real Colégio das Artes: entre a sua matriz e outra
}

Autor(es): Miranda, Margarida

Publicado por: Faculdade de Letras da Universidade de Coimbra

URL persistente:

URI:http://hdl.handle.net/10316.2/32379

DOI:

DOI:http://dx.doi.org/10.14195/0870-4112_9_1

Accessed : $\quad$ 26-Apr-2023 11:56:29

A navegação consulta e descarregamento dos títulos inseridos nas Bibliotecas Digitais UC Digitalis, UC Pombalina e UC Impactum, pressupõem a aceitação plena e sem reservas dos Termos e Condições de Uso destas Bibliotecas Digitais, disponíveis em https://digitalis.uc.pt/pt-pt/termos.

Conforme exposto nos referidos Termos e Condições de Uso, o descarregamento de títulos de acesso restrito requer uma licença válida de autorização devendo o utilizador aceder ao(s) documento(s) a partir de um endereço de IP da instituição detentora da supramencionada licença.

Ao utilizador é apenas permitido o descarregamento para uso pessoal, pelo que o emprego do(s) título(s) descarregado(s) para outro fim, designadamente comercial, carece de autorização do respetivo autor ou editor da obra.

Na medida em que todas as obras da UC Digitalis se encontram protegidas pelo Código do Direito de Autor e Direitos Conexos e demais legislação aplicável, toda a cópia, parcial ou total, deste documento, nos casos em que é legalmente admitida, deverá conter ou fazer-se acompanhar por este aviso.

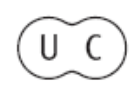



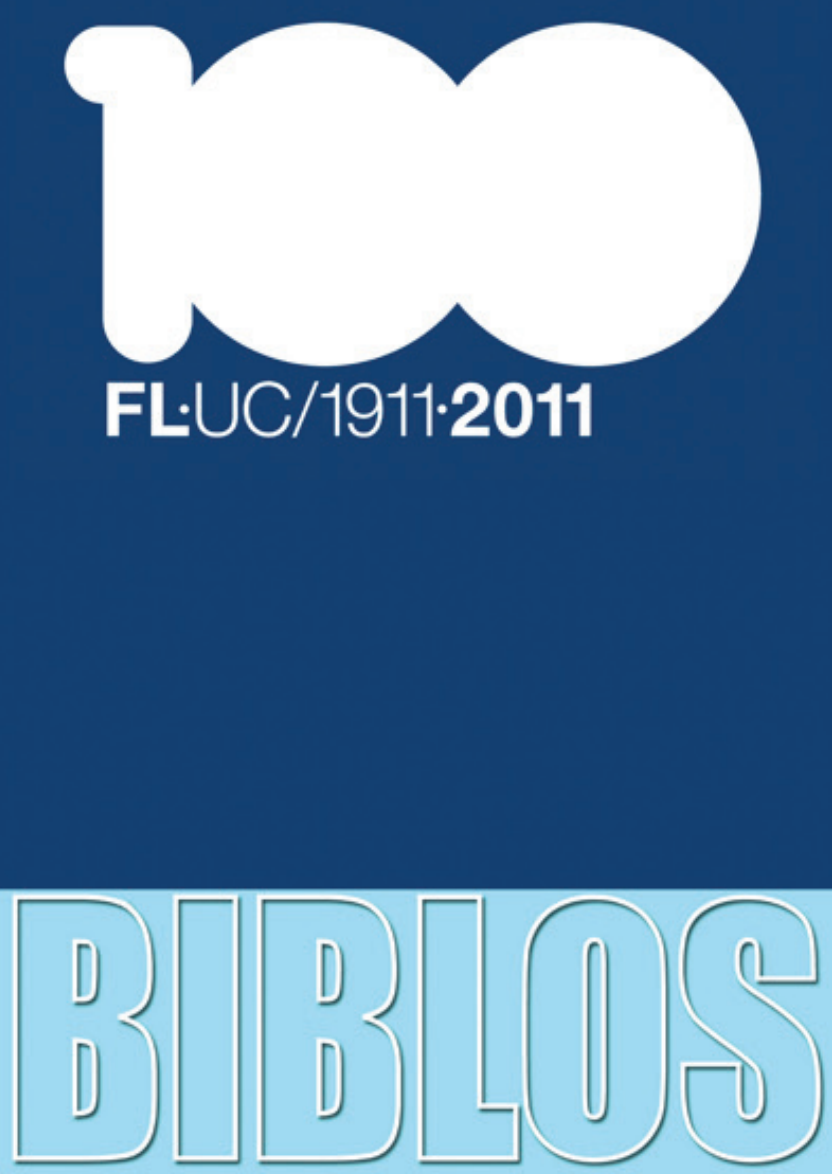

REVISTA DA FACULDADE DE LETRAS UNIVERSIDADE DE COIMBRA 
Biblos, n. s. IX (2011) 11-31

Margarida Miranda

Universidade de Coimbra

\section{AS ARTES DO REAL COLÉGIO DAS ARTES. ENTRE A SUA MATRIZ E OUTRA}

\section{Resumo}

Após o estudo de noções como artes liberales e humanitas em Cícero, e após o exame de alguns documentos sobre o ensino no Colégio das Artes, este estudo pretende mostrar que as artes do Colégio eram tributárias, mais do humanismo de Cícero e da humanitas litterarum proclamada em defesa do poeta Árquias, do que da tradição medieval do trívio e do quadrívio. Formalmente concebido como alternativa à Universidade (conquanto fosse dela parte integrante) para promover o saber humanístico e fazer renascer os estudos clássicos, principalmente as litterae humaniores, o Real Colégio das Artes de Coimbra era muito mais do que o conjunto dos Professores de Artes.

$\mathrm{Se}$ as litterae humaniores ou artes humaniores do Colégio das Artes designavam disciplinas como a gramática, a retórica, a filosofia, a poesia, e a história, hoje essas disciplinas correspondem a um conjunto de artes e de saberes que incluem, além da história e da filosofia, os estudos linguísticos e os estudos literários, entre outros. A Faculdade de Letras é pois, do ponto de vista cultural, intelectual, institucional, a instituição que naturalmente sucede ao Colégio das Artes. O seu capital simbólico constitui património imaterial da Faculdade de Letras. Ora, podemos nós alienar esse património, sem prejuízo das artes humaniores que professamos? Não estaremos a ser coniventes com a fragmentação de saberes que secundariza quotidianamente as Humanidades? Nos diplomas com que confere os seus graus académicos, a Faculdade de Letras continua a autodesignar-se Liberalium Artium Facultas. É que, na realidade, nem as mudanças de paradigma se impõem por decisão discricionária, nem o actual Colégio das Artes pode suprimir da memória a riqueza simbólica do título que carrega.

Palavras-Chave: Humanismo, Humanidades Clássicas, Artes, Colégio das Artes, Faculdade de Letras, Colégio Trilingue. 


\begin{abstract}
Drawing upon notions such as artes liberales and humanitas in Cicero, and upon the analysis of documents concerning the curriculum at the Royal College of Arts, the author argues that the artes taught at the College were closer to the humanism of Cicero and the humanitas litterarum proclaimed in support of the poet Archias than to the medieval trivium et quatrivium tradition. Created as an alternative to the University, though actually being a part of it, and aiming to promote the humanities and the rebirth of classical studies, especially the litterae humaniores, the Royal College of Arts at Coimbra included other faculty members besides teachers of Arts. The litterae humaniores or artes humaniores encompassed grammar, rhetoric, philosophy, poetry, and history, which correspond today to a number of fields that include, besides history and philosophy, linguistic studies and literary studies, among others. From an institutional, intellectual and cultural point of view, the Faculty of Arts and Humanities is thus the natural heir of the College of Arts. The latter's symbolic capital is the immaterial heritage of the Faculty of Arts Humanities. Can we alienate this heritage without prejudice to the artes humaniores that we profess? Are we not being complicit with the fragmentation of knowledges that daily undervalues the humanities? In the diplomas that confer its academic degrees, the Faculty of Arts and Humanities is still referred to as Liberalium Artium Facultas. In fact, neither can arbitrary decisions impose paradigm changes, nor can the present College of Arts suppress from memory the symbolic richness of its name.
\end{abstract}

Keywords: Humanism, Classical Humanities, Arts, College of Arts, Faculty of Arts and Humanities, Trilingual College. 


\section{A humanitas de Cícero e o discurso Pro Archia poeta. As artes liberales}

... omnes artes, quae ad humanitatem pertinent, habent quoddam commune vinculum, et quasi cognatione quadam inter se continentur. (Cic. Pro Arch.1.2)

«... todos os ramos do saber atinentes à cultura humana têm como que um vínculo comum e estão ligados, digamos assim, por um certo grau de parentesco» (Trad. de C. A. Fonseca 1974: 183).

É com a proclamação da unidade dos saberes, em pleno tribunal, que Cícero dá início à defesa de Árquias, o poeta acusado de usurpar o título de cidadão romano. Cedo, porém, o leitor se apercebe de que, em nome daquele poeta que outrora fora seu mestre, o orador sobrepõe ao aspecto propriamente jurídico da questão uma causa bem mais ambiciosa: enaltecer as letras e a cultura literária diante de uma sociedade que preferia a grandeza militar e que, nas letras, não via mais do que o alheamento da respublica.

O discurso em favor do poeta Árquias tornou-se assim o primeiro texto destinado a chamar a atenção para a importância das letras e da actividade literária, quer do ponto de vista individual quer do ponto de vista social e colectivo. Não se trata, como se sabe, de uma obra-prima da eloquência forense, mas o discurso alcançou justamente o estatuto de Magna Charta do Humanismo, desde o momento em que Petrarca o descobriu em Liège (1333) e o difundiu na Itália e na Europa. Do ponto de vista histórico-cultural e literário, a defesa do poeta Árquias inaugura conceitos fundadores da cultura europeia, recheados de interesse para uma Faculdade que se celebra como lugar das Letras, das Artes, das Humanidades e da Cultura Humanística, e como espaço de recriação de novos saberes.

Um desses conceitos fundadores corresponde ao termo humanitas (omnes artes quae ad humanitatem pertinent...), um termo particularmente difícil de traduzir, mas que neste mesmo contexto faz ecoar a sentença imortal de Terêncio: homo sum... (sou homem. Nada do que é humano me é alheio). Em ambos os autores e em ambos os termos (em Cícero humanitas, em Terêncio humanus), a mesma largueza de significado e o mesmo sublinhar dos vínculos que unem diferentes seres 
da mesma natureza, numa mesma realidade. Numa primeira acepção, a humanitas de Cícero é entendida como aquela característica que define o homem como homem; aquilo que vincula um ser humano a outro e aos seres humanos em geral - como o termo grego philantropia. No entanto, aquilo que forma o homem como homem são as litterae et artes, o que faz com que a humanitas do Pro Archia não seja sinónimo de philantropia mas antes de paideia, nomeadamente da paideia helenística. Neste segundo sentido, portanto, o homo humanus opôs-se ao barbarus, e assim subsistiu como ideal de vida e de cultura, quando o Cristianismo o adoptou e o transmitiu à Europa.

Que significava pois esta humanitas de que nos fala Cícero, a humanitas que deslumbrou Petrarca e os intelectuais conhecidos como humanistas? E quais eram aquelas artes quae ad humanitatem pertinent...?

Já antes, no parágrafo inicial do discurso, a propósito das três qualidades indispensáveis ao bom orador - o talento (ingenium), os conhecimentos teóricos (ratio) e a prática oratória (exercitatio dicendi) o orador se referira às optimae artes como aquelas às quais, durante toda a sua vida, dedicara estudo sistemático (Pro Arch. 1.1). No tempo de Cícero, essas optimae artes correspondiam aos estudos literários e filosóficos (litterae), também designados artes ingenuae (ou artes intelectuais), artes bonae, ou artes liberales, isto é, próprias do homem livre. Eram elas que compunham a variedade de saberes da humanitas de Cícero, de acordo com o princípio, aliás, confessadamente herdado de Platão (De Oratore 31), da união íntima entre os diversos ramos da cultura ${ }^{1}$.

Falacioso seria pois entender a humanitas de Cícero no sentido de 'humanidade', a palavra que lhe está mais próxima. A humanitas de que nos fala Cícero no Pro Archia é antes a doctrina ingenuarum et humanarum artium com que o autor do De Oratore (31 e 32) descreve o saber enciclopédico de Hípias e a universalidade do saber dos oradores.

${ }^{1}$ No debate actual sobre a unidade do saber - túnica inconsútil que se dissociou em parcelas cada vez mais diminutas - bastará evocar o pensamento filosófico de Georges Gusdorf, um dos maiores defensores em França do pensamento interdisciplinar. A sua vasta obra enciclopédica, Les Sciences humaines et la pensée occidentale I-XIII, Paris, 1966-88, entre muitos outros títulos que dedicou à questão, continua sendo uma referência. 
A humanitas do Pro Archia corresponde afinal, como vimos, à noção grega de paideia, com os seus três ramos principais do saber: litterae (letras), música (que entre os gregos não tinha ainda o sentido restrito que depois adquiriu) e palaestra (ginástica). Eram esses os principais elementos da educação grega, orientada para a formação integral do homem, a enkyklios paideia.

Ao receber a lição dos gregos, Cícero verte, portanto, no termo humanitas o conteúdo da paideia helénica, exprimindo assim, mais do que a simples instrução literária, tudo quanto constituía a cultura humana e, simultaneamente, também o processo que a ela conduzia. É essa, aliás, a interpretação do próprio Aulo Gélio, gramático e erudito latino do século II d.C. quando, nas Noites Áticas (13.17), reflecte sobre o sentido daqueles termos (humanitas e paideia) e os descreve como eruditionem institutionemque in bonas artes.

Qual a propriedade do termo latino humanitas para um conceito tão helénico, Aulo Gélio também o explica a seguir: se a palavra e a razão são as faculdades que distinguem os homens dos animais, então tornam-se mais humanos todos quantos se dedicam àqueles estudos. Assim se compreende que as artes ingenuae acabassem por receber também o nome de artes humaniores.

Se as letras, a música e a ginástica eram os três ramos principais do saber que a paideia grega integrava, não há dúvida de que, no pensamento de Cícero, aqueles três ramos são reequacionados de forma bem diferente. Da leitura do Pro Archia, o que resulta claro é o primado das letras sobre os outros ramos do saber, entendendo por 'letras' saberes como a gramática, a retórica a filosofia, a poesia e a historiografia. Esses saberes constituíam o alimento e a cultura do espírito. Assim, o título que até aí cabia genericamente aos três ramos (artes) da humanitas ou da paideia passou a designar especificamente as letras. Por uma espécie de sinédoque, as letras sobrepuseram-se aos outros ramos do saber e passaram a ser consideradas as optimae artes, as artes por excelência, absorvendo assim o título que antes pertencia propriamente ao conjunto dos ramos da humanitas. As letras designam então as artes liberales, as artes ingenuae ou ainda as artes bonae, e adquirem a noção ampla de 'cultura', mais do que 'instrução literária'. Quando Cícero usa expressões como de studiis humanitatis ac litterarum (II.3) e quando mais à frente se refere às graecarum artium ac disciplinarum (III.5), tem consciência de que está a excluir e até 
mesmo a pressupor a oposição de um outro saber, o saber jurídico e a própria oratória forense. Com efeito, é à cultura humanística e literária que se quer referir no primeiro caso (II.3), nomeadamente à filosofia e à literatura grega (III.5), distinguindo o saber humanístico do saber propriamente jurídico, mas alargando-o definitivamente e estendendo-o muito além da retórica e da filosofia dialéctica.

É a noção da unidade dos saberes que domina o pensamento de Cícero. As artes liberales são, pois, aquelas artes por meio das quais se cultiva o espírito e se obtém a cultura do homem livre (a humanitas). Nesse sentido, elas são também, com toda a propriedade, artes humaniores - na medida em que humanizam o homem e aperfeiçoam a sua natureza.

Foi essa humanitas que no séc. XIV deslumbrou Petrarca e os humanistas. A descoberta do Pro Archia poeta, em 1333, fez daquele discurso a magna charta do humanismo, não por ser simplesmente a defesa de um poeta, nem por ser, de certo modo, a própria defesa de Cícero e da sua dedicação pessoal às letras, mas antes por ser a defesa da humanitas - isto é, a defesa do saber e da actividade literária, que conduzia o homem em direcção à realização plena da sua humanidade . Propondo o cultivo geral de todas as capacidades do homem, o discurso em defesa do poeta Árquias tornou-se um antecedente da cultura humanística moderna.

\section{Um colégio onde se hão-de ler todas as artes}

Sabemos quanto a fundação do Colégio das Artes, em 1547, foi fruto do fervor humanístico que presidia à reforma dos estudos realizada por D. João III. Efectivamente, a redescoberta das humanidades clássicas operou uma transformação não apenas nos estudos literários como na própria hierarquia dos saberes.

O humanismo do Renascimento não era, na sua substância, um sistema filosófico, dotado de um conjunto formal de doutrinas embora tenha tido numerosas implicações filosóficas - mas antes um programa cultural e pedagógico centrado precisamente na valorização e desenvolvimento dos studia humanitatis, e no renascer do saber Antigo (Paul Kristeller 1995). Entre as disciplinas designadas por studia humanitatis, ocupava agora um lugar proeminente, não a filosofia, 
o direito ou a medicina, mas antes aquilo que hoje se pode designar por estudos literários, os quais incluíam por sua vez os estudos linguísticos, a história, a filosofia moral... No topo desse novo curriculum de estudos estava a retórica, saber supremo, que abrangia todos os outros saberes e os levava à perfeição, uma retórica essencialmente tributária de Cícero, capaz de unir eloquência e sabedoria, e assente na convicção de que, para pensar e comunicar bem era necessário conhecer, estudar e imitar os autores antigos.

Era esta equação de saberes que presidia ao Colégio das Artes, e não simplesmente o cânone medieval das artes liberais, com a tradicional organização das disciplinas em triuium (gramática, retórica e dialéctica) e em quadriuium (aritmétrica, geometria, astronomia e música) que, no século XII, dera lugar ao quadro institucional das Faculdades de Artes tal como no-las descreve o livro de Olga Weijers e Louis Holtz (1997). As artes que davam o nome ao Real Colégio das Artes correspondiam a um projecto de renovação dos saberes que se traduzia no regresso às origens, mais do que na continuação do ensino da Latinidade, aliás já praticado na Universidade e no Mosteiro de Santa Cruz.

Baluarte da renovação das instituições escolares no reinado de D. João III², o Real Colégio das Artes, inaugurado em 1548, era formalmente concebido como alternativa à Universidade (conquanto fosse dela parte integrante), para promover o saber humanístico e fazer renascer os estudos clássicos, principalmente as litterae humaniores. Para isso o monarca chamava ao reino André de Gouveia e os mestres portugueses que se tinham formado em França, e que ali tinham mantido instituições escolares célebres - como o Colégio de Santa Bárbara, em Paris, ou o Colégio de Guiena, na cidade de Bordéus. O reino de Portugal podia enfim obter o retorno das gerações de bolseiros que o monarca enviara sucessivamente para Paris.

${ }^{2}$ A renovação das instituições escolares já é visível na oração pronunciada por André de Resende em Lisboa, em 1534, por ocasião da abertura da Universidade (Oratio pro rostris). O fenómeno continua, depois, com a criação de escolas que, embora menos ambiciosas, podem ser consideradas antecedentes do Real Colégio das Artes, como o colégio do Convento de Penha Longa, criado por Frei Diogo de Murça em 1535 e depois transferido para Santa Marinha da Costa, em Guimarães; ou a escola de Latinidade, criada em Braga pelo Infante D. Henrique, onde ensinou Clenardo ou a escola de Évora. 
Na medida em que a nova fundação tinha por missão promover o saber humanístico, o Real Colégio das Artes de Coimbra era também uma réplica do Collège Royal (1530), que Francisco I criara em França a pedido de Guillaume de Budé, e para cujo corpo docente fora convidado o próprio Erasmo. O Collège Royal, por sua vez, inspirava-se no Colégio Trilingue de Lovaina (1517), fundado postumamente por Jerónimo de Busleiden, mas inspirado e tutelado pelo próprio Erasmo, para acender no meio académico a chama do humanismo, e para desenvolver o estudo das três línguas, o Latim, o Grego e o Hebraico. Antes mesmo do Colégio Real de França, em 1528, a Universidade de Alcalá vira também nascer o seu Colégio Trilingue (ou de S. Jerónimo), de onde irradiavam os estudos literários, enquanto a Universidade de Salamanca viria a criar o seu Trilingue muito mais tarde, em 1554.

Todas estas instituições gozavam de uma intencionalidade e uma motivação comum: difundir o humanismo e as bonae artes, junto de Universidades que tradicionalmente lhes não eram favoráveis. A inspirar os fundadores de todas estas instituições, encontrava-se outro humanista de referência: Erasmo, para quem os studia humanitatis haviam de conduzir à renovação da teologia, pelo estudo das três línguas sagradas, o Latim, o Grego e o Hebraico. De facto, é Erasmo quem organiza, em Lovaina, o Colégio Trilingue, após a morte do seu mecenas; é Erasmo que Francisco I de França convida para ensinar no Collège Royal; é Erasmo que D. João III também convida para ensinar em Coimbra, não obstante ter o humanista declinado ambos os convites.

O humanismo cristão de Erasmo, que preside à cultura humanística das novas instituições escolares e alimenta nelas a renovação dos saberes, é ainda o mesmo que fundamenta a aliança entre saber sagrado e saber profano, entre letras pagãs e sabedoria cristã. Não é de espantar, assim, que a filosofia e as ciências naturais continuassem de certa forma ancillae theologiae, como se deduz de um documento nascido ao longo da mesma época, Ratio Studiorum dos colégios dos Jesuítas.

Uma vez que as artes liberais e as ciências naturais predispõem o intelecto para a teologia, estão ao serviço do seu perfeito conhecimento e da sua aplicação prática e contribuem por si só para esse fim, o professor de filosofia deverá tratá-las com toda a diligência... (IX.1)

A filosofia e as ciências naturais eram saberes ao serviço da teologia. Nisso consistia, afinal, a unidade do saber humanístico: na cooperação 
do saber pagão com o saber cristão, as duas vias - independentes mas não adversárias - a percorrer na busca da verdade.

Se a filosofia e as ciências naturais eram instrumentos da teologia, eram-no também a retórica, os estudos literários e a produção literária dos clássicos pagãos, já que ao conhecimento do Criador chegava-se através do conhecimento das suas criaturas. O humanismo cristão operava assim na Europa uma reconfiguração dos saberes que acabaria por elevar de modo irreversível o estatuto dos estudos literários.

O exame de diversos documentos que espelham directa ou indirectamente o programa cultural e pedagógico do Colégio permite pensar que as artes do Colégio eram mais tributárias do humanismo de Cícero e da humanitas litterarum proclamada em defesa do poeta Árquias, do que da tradição medieval do trívio e do quadrívio, que aliás era absorvida no seio do humanismo renascentista.

\subsection{O nome do Colégio}

Comecemos pela designação dada ao Colégio. Nem sempre, como sabemos, o colégio recebeu o título de Colégio das Artes, que o uso consagrou. A acta do Conselho da Universidade de 19 de Julho de 1547 designa-o simplesmente como «colegio de $\mathrm{m}^{\text {te }}$ André», atribuindo, aliás, ao humanista o lugar que lhe era merecido como co-fundador e autor do respectivo plano de estudos (Brandão 1924: 354). «Colégio do Mestre André» é também a designação que lhe dá uma carta do Bispo de Coimbra ao Rei, em 1548, manifestando o júbilo da cidade pela nova instituição (Brandão 1924: 355). O título de «Colégio das Artes» aparece, no entanto, desde o Primeiro Regimento que El Rei Dom João Terceiro deu ao Colégio das Artes no tempo que em ele leram os Franceses, de 16 de Novembro de 1547, e suplantaria outros, como «Real Colégio» ou «Colégio Real», «Regium Gymnasium» (nos estatutos de André de Gouveia), «Colégio das Artes e Humanidades» ${ }^{3}$, «Colégio d'el Rei», «Colégio da Universidade de Coimbra», ou ainda «Colégio dos Franceses» (Brandão 1924: 356-361).

${ }^{3}$ Por exemplo, no Regimento que os porteiros do collegio real das Artes $e$ Humanidades hão-de guardar, documento que completa os estatutos de 1548 (Ferreira, 1944: 306-308). 
Porquê «Colégio das Artes»? Qual a propriedade da designação? Qual o ensino nele ministrado?

Mário Brandão (1924:357) sugere a hipótese, bastante plausível, de que tenha sido André de Gouveia o autor do nome. Na verdade, ao atribuir o título de «Colégio das Artes», o Principal do Colégio de Coimbra mais não fazia do que recuperar o título da instituição que, em Bordéus, antecedera o Colégio de Guiena (outrora Collége des Arts), cujo governo ele viera a herdar depois da sua transformação, em 1533. Designando o novo colégio como «Colégio das Artes», é evidente que André de Gouveia não circunscrevia o termo artes ao novo significado restrito que ele havia alcançado, associado agora à filosofia aristotélica, para designar os estudos próprios das Faculdades de Artes. No termo artes, o Principal do Colégio abrangia antes o campo mais vasto das artes liberales estabelecidas por Cícero e ininterruptamente transmitidas nas disciplinas do triuium (gramática, retórica e dialéctica), então renovadas pela filologia humanística.

O Rei, aliás, parecia dar às artes do Colégio o mesmo sentido lato que lhe dava André de Gouveia. Quando escrevera ao Prior do Mosteiro de Santa Cruz comunicando-lhe a necessidade de instalações para a nova escola, Dom João III apresentara o colégio como hum collegio em que se hão-de ler todas as artes (Brandão 1924:271). ${ }^{4}$ Era sob esta forma algo indefinida, é certo, que o fundador definia a instrução a ministrar no novo colégio. Mas ele não podia deixar de ter no horizonte a especificidade de escolas como o Collège Royal, o Colégio de Santa Bárbara, o Colégio de Guiena ou o Colégio de Lovaina, a que aludimos supra. As artes do Colégio iriam abraçar não só a tradicional filosofia, que era pertença da Faculdade de Artes, como também os saberes renovados da gramática, da retórica, da poesia e da historiografia, abrindo as portas da Universidade a todo o campo das letras pagãs e da filologia humanística.

No Regimento de 1547, o fundador é mais explícito e determina claramente as matérias a ensinar. Segundo aquele documento, o Colégio destina-se a todos quantos «quiserem ir aprender Latim, Grego,

${ }^{4}$ Devemos porém recordar que a expressão todas as artes já fizera história na Universidade portuguesa. Em carta de 1290, D. Dinis alude ao Estudo Geral de Lisboa, e ali refere também tê-lo munido «com cópia de doutores em todas as artes» (Moreira de Sá 1966: n. ${ }^{\circ} 4$ e 5). 
Hebraico, Matemáticas, Lógica e Filosofia» (Ferreira 1944: 283 §1). Para isso o monarca determina que haja dezasseis regentes: dois para ensinar a ler, escrever, declinar, e conjugar; e oito para lerem Gramática, Retórica e Poesia; três para o Curso das Artes; e os outros três para lerem Hebraico, Grego e Matemáticas» (\$3). O Colégio das Artes era portanto muito mais do que os três docentes que regiam o curso de Artes. Destinava o maior número de docentes a disciplinas como a Gramática, a Retórica e a Poesia e abria lugar ao estudo dos Auctores que andavam afastados do curriculum universitário. ${ }^{5}$ Por isso Mário Brandão (1924: 277) na sua monografia sobre o Colégio das Artes regista, sem hesitar, que «[no Colégio] se cuidou mais de fazer brilhar as Boas-letras que as argúcias da Filosofia».

Que a filologia humanística introduzida em 1547 vinha suprir uma lacuna sentida pela própria Universidade desde 1541, também parece claro. Nessa data, o reitor escreveu a D. João III pedindo-lhe que ouvisse o Mestre João Fernandes (outrora professor em Salamanca e Alcalá e agora mestre de prestígio em Coimbra) sobre as dificuldades que atravessava o ensino da Latinidade na Academia. Aos rogos do reitor sobre «a falta» que havia na Universidade «nos princípios de latinidade», respondeu o monarca pedindo à Universidade que determinasse então as medidas a tomar, sob conselho do referido mestre. Embora não conheçamos as medidas aconselhadas ao monarca, é muito provável que a criação do Colégio fosse assim a resposta perfeita às faltas em Latinidade, denunciadas pelo próprio João Fernandes (Brandão, 1924: 62).

Em que consistiu, pois, a reforma do ensino da Latinidade operada pelo Colégio das Artes?

${ }^{5}$ Segundo os estatutos manuelinos de 1503, as disciplinas ensinadas na Faculdade de Artes eram filosofia natural e filosofia moral, lógica, gramática, e astronomia. Já segundo a Carta de doação ao Infante Dom Henrique, de 12 de Outubro de 1431, as disciplinas eram gramática, lógica, retórica, aritmética, música, geometria, astrologia, e filosofia natural e moral. No entanto, nos estatutos do Estudo Geral do mesmo ano (1431), a lista reduz-se a gramática e lógica. De facto, enunciar as disciplinas sob a designação de gramática, lógica, filosofia natural e filosofia moral não quer dizer que estivessem totalmente excluídos os estudos de retórica. Informações mais detalhadas sobre as disciplinas ensinadas no Estudo Geral de Lisboa e de Coimbra podem ler-se em Maria Cândida M. Pacheco 1997: 170 ss. 


\subsection{A Docendi Ratio de André de Gouveia}

Para conhecer as artes do Colégio examinámos diversos documentos que espelham directa e indirectamente o ensino ali praticado:

Os Estatutos do Colégio das Artes de 26 de Abril de 1548, que seguimos na edição de Ferreira, 1944: 295-308, são naturalmente decalcados sobre o texto dos Statuta Gymnasii Aquitanici, com poucas variantes linguísticas e as necessárias adaptações à realidade local. De resto, o sentido das considerações iniciais no interesse pelas bonae artes é literalmente o mesmo:

Quoniam primum fundamentum optimae cujusque scholae ipsa est scholastica disciplina, in primis danda opera est, ut in hoc Regio Gymnasio non solum bonae litterae floreant, sed etiam boni mores, adjutore Deo, semper obseruentur. (Ferreira 1944: 295)

De acordo com os ideais humanísticos do seu tempo, as boas letras deveriam andar a par dos bons costumes. De facto, os Estatutos do Colégio das Artes estabelecem normas de conduta, costumes, práticas escolares concretas bem como práticas religiosas, horários, pausas e feriados, mas nada dizem acerca dos planos de estudos e dos programas ${ }^{6}$. Esses, encontramo-los descritos na Schola Aquitanica, a regra de Bordéus criada por André de Gouveia quando ali exerceu as funções de Principal naturalmente transposta para Coimbra. O seu texto latino é reproduzido por Ferreira 1944: 254-272 e merece ser lido na íntegra, já que Mário Brandão (1924: 280) não o conheceu senão por via de um resumo, da responsabilidade de Frei Fortunato de S. Boaventura.

André de Gouveia, que fora o segundo Principal do Colégio de Guiena e o autor do seu programa de estudos, não podia deixar de trazer para Coimbra as linhas definidoras do ensino ali experimentado. Consignara-as sob a forma de regulamento ou plano de estudos, e Elias Vinet publicá-las-ia anos mais tarde, em 1583, sob o título de Schola Aquitanica. A decisão da publicação, a que não foi alheio o próprio Montaigne, partiu das autoridades da Cidade, para que a regra até então

${ }^{6}$ Um dos capítulos mais interessantes Oeconomia Seruanda in Gymnasio Regio, onde se trata dos horários quotidianos das prelecções, disputas, cerimónias religiosas, refeições, estudo, recreio e repouso, foi traduzido por Ramalho 1998: 188-199. 
observada no Colégio de Bordéus não pudesse ser facilmente alterada. No prefácio, porém, Elias Vinet atribui claramente a obra ao seu verdadeiro autor: André de Gouveia (Andreas Gouveanus Lusitanus).

Ao vir para Coimbra com a missão de fundar um Colégio das Artes, o humanista não trazia apenas os programas e os planos de estudos já experimentados em Bordéus. Trazia também os melhores dos seus companheiros para pôr em prática aquele projecto: Nicolau de Grouchy, Elias Vinet, Diogo de Teive, Arnaldo Fabrício, Guilherme Guerente, Jorge Buchanan e João da Costa. Sinal do compromisso deliberado com reforma efectiva da latinidade é o facto de, de entre aquela geração de mestres conhecidos como 'os bordaleses', ter ensinado filosofia no Colégio apenas um bordalês, observa Mário Brandão (1924: 277), quando todos os outros ocuparam as cátedras de Latim e Humanidades.

Intitula-se o documento Docendi ratio in ludo Burdigalensi, e as primeiras palavras são para definir a verdadeira natureza de uma escola que recebera o nome de Schola Aquitanica, por se situar na capital daquela província considerada mercatum bonarum artium, mas que era afinal um gymnasium humaniorum litterarum (Ferreira 1944: 255) ${ }^{7}$.

Seguidamente, estabelecem-se os programas de cada uma das dez classes de Humanidades, designadas pela ordem decrescente.

A Décima corresponde à iniciação na leitura e na escrita e é, mais uma vez, ocasião para lembrar a prioridade do conhecimento da língua latina: latino sermone cognoscendo haec schola in primis destinata est...

Já na Nona encontramos o propósito de que os alunos aprendam a ler e a escrever, bem e com rapidez, o latim e a língua materna (ut pueri bene et uelociter latina gallicaque legere et scribere perdiscant), além de aprenderem a flexão dos nomes e dos verbos e os primeiros elementos de gramática, recitando pequenas sentenças tiradas dos Dísticos de Catão e dos Dicta Sapientium de Erasmo.

Quando são considerados aptos, os alunos passam à Oitava, cujo programa contém cartas escolhidas de Cícero e algumas cenas das

${ }^{7}$ Burdigalensis schola, cui humaniorum litterarum gymnasio, Aquitanicae quoque sholae cognomen impositum fuit, quod et Burdigala Aquitaniae, suae prouinciae, caput sit, et quod uniuersae Aquitaniae iuuentus Burdigalam tanquam ad mercatum bonarum artium, cuncta confluat. 
Comédias de Terêncio ${ }^{8}$, tendo em vista a aquisição da língua para a conversação.

Na Sétima, continuam as Cartas de Cícero Ad Familiares e têm início as composições escritas corrigidas pelo mestre, ao mesmo tempo que se avança no estudo da gramática por meio daquilo que se designa como Declinationum et Rudimentorum Grammatices Libri (correspondentes à gramática elementar) e dos livros de Despautério, autor que havia de acompanhar os alunos até quase ao fim do curso.

Na Sexta, estuda-se mais um livro das Cartas de Cícero Ad Familiares e avança-se na gramática de Despautério, dando especial atenção à sintaxe. A Quinta retoma quer as Cartas de Cícero - novo livro das Epistolae ad Familiares - quer os livros de Despautério (De quantitate syllaborum, De figuris), mas introduz o estudo dos poetas e da versificação latina. O programa desta classe incluía ainda uma comédia de Terêncio (Terentii comoediarum aliqua) e, no fim do ano, uma das Epistolae ex Ponto, de Ovídio.

Os estudos de oratória e de Retórica começam na Quarta classe ${ }^{9}$. Cícero é ainda o autor privilegiado (mais um livro das Epistolae ad Familiares ou então das Epistolae ad Atticum), mas às cartas seguia-se um dos discursos mais simples de Cícero bem como um resumo de Retórica que fosse muito fácil (compendium aliquot Rhetorices ex facilioribus). Ao mesmo tempo, retomava-se o estudo dos livros de Despautério, a fim de rever a sintaxe, a versificação e as figuras. O programa incluía ainda outra comédia de Terêncio e alguns poemas de Ovídio, tirados dos Tristia ou das Epistolae ex Ponto, textos que deviam ser ditos de memória, depois de estudados. Ao mesmo tempo, aumentava o número e a extensão das composições escritas, podendo mesmo incluir algumas em verso. É bem notória a transição que se processa nesta classe, de tal modo que o número de autores e a variedade de textos a estudar alargavam-se consideravelmente.

${ }^{8}$ Os Colloquia de Maturin Cordier, que Mário Brandão parece aceitar no plano de estudos de Coimbra (1924: 281), não deverão ter feito parte do programa de Coimbra, pois a sua publicação data de 1564. A obra deverá ter sido acrescentada por Elias Vinet.

${ }^{9}$ No programa da Primeira Classe lê-se: Et si haec quae praecedunt, grammaticorum classes sunt omnes, tamen in quattuor superioribus et praecipue in hac prima tractatur Rhetorica. 
$\mathrm{Na}$ Terceira classe estudam-se ainda as Cartas de Cícero (aos Familiares, ou a Ático, ou a Bruto ou a seu irmão Quinto), idque gallice, isto é, apreciavam-se as cartas no original latino, mas o seu estudo era feito na língua materna, ao contrário da prática jesuítica que consagraria uma clara preferência pela língua latina. Em seguida, o programa propunha nova Oração de Cícero, juntamente com os preceitos de Retórica ex aliquo scriptore optimo. $\mathrm{O}$ aluno continuava a estudar os livros de Despautério sobre sintaxe, sobre versificação e ainda o De figuris, seguidos de uma comédia de Terêncio. O programa ficava completo com a leitura e explicação de Ovídio (dos Fastos ou das Metamorfoses).

Na Segunda classe acentua-se a preferência pela oratória. Prescreve-se uma oração de Cícero e as Partitiones Oratoriae (diálogo de Cícero sobre as partes da oratória), mas introduzem-se os historiadores e os poetas também são objecto de estudo: Virgílio, Ovídio e Lucano (Pharsalia). À Segunda classe recomenda-se ainda o exercício das declamationes, privadas e públicas, para as quais os alunos já vinham sendo preparados desde a classe quarta.

A Primeira classe correspondia, portanto, ao último nível dos estudos de Retórica: «in quattuor superioribus et praecipue in hac prima tractatur Rhetorica». O programa da Primeira classe repartia-se assim entre Cícero e Quintiliano, para o estudo dos preceitos de oratória; os discursos de Cícero ou alguma das suas obras morais, para aplicação daqueles preceitos; e ainda a história, onde figuram, entre outros, autores como Tito-Lívio, São Justino Mártir (autor de escritos apologéticos, martirizado por Marco Aurélio), Séneca, Eutrópio (autor do Breviarium historiae Romanae) e Pompónio Mela (autor do "De Chorographia"). Nova recomendação é feita sobre as declamationes, agora obrigatórias: declamationes de carácter privado, isto é, diante da própria classe, aos Sábados de manhã; e declamationes em público, isto é, diante de todo o colégio convocado ao som do sino, aos Domingos à tarde.

Não me deterei sobre o programa de Filosofia da Schola Aquitanica senão para observar que, nas brevíssimas palavras que esta Ratio lhe dedica, encontramos as indispensáveis obras de Aristóteles, obrigatórias em todas as Faculdades de Artes. No entanto, a Schola Aquitanica reduzira os estudos de filosofia a dois anos (dois cursos e dois mestres), o dos dialécticos ou dos lógicos e o dos físicos, de acordo com as 
matérias de que se ocupavam os estudantes, ao passo que em Coimbra, o estudo das Artes continuou sendo de três anos e meio, até 1549, quando D. João III decretou que fosse reduzido para três anos, contra os protestos da Universidade. Podemos, porém, assegurar que, se Grouchy, o Mestre de Dialéctica em França, comentara Aristóteles na língua original, também aqui o faria, nas lições que lhe foram atribuídas.

Os estudos de Grego e de Matemática, que também faziam parte do curriculum, são tratados no capítulo Publicae praelectiones. O programa de Grego, que tinha a duração de um só ano, repartia-se entre a Gramática de Teodoro de Gaza (ou outra à escolha do professor) e a leitura de Homero e de Demóstenes. O curso era destinado a todos os alunos, principalmente os que frequentavam as classes mais adiantadas de Gramática, desde a Quinta, e permitia aos alunos conhecer Aristóteles na língua original.

Já a Matemática durava dois anos e não um, como parece sugerir Mário Brandão (1924: 285). O curso podia ser frequentado por todos os escolares, mas estava sobretudo destinado aos alunos da Segunda e Primeira Classe de Gramática e aos alunos de Filosofia. O programa ocupava-se de aritmética, ${ }^{10}$ geometria e astronomia, e incluía os Elementos de Euclides, o tratado Da Esfera e outros autores gregos e latinos à escolha do professor, dum biennium compleatur (desde que não excedesse os dois anos).

Apesar de na Docendi Ratio in ludo Burdigalensi ou Schola Aquitanica não encontrarmos qualquer alusão ao estudo do Hebraico, Mário Brandão (1924: 284) toma como certo o seu estudo, num terceiro

${ }^{10}$ A Schola Aquitanica refere-se de modo omisso a uma Logistica Burdigalae, que corresponde a uma obra do próprio Elias Vinet, que o autor não identificou por modéstia: Eliae Vineti Santonis de Logistica libri tres Burdigalae, apud Simonem Millangium, 1573. Mas esta, como se vê, ainda não existia no tempo de André de Gouveia. A mesma questão se coloca em relação a outra obra ali referida: Pselli Mathematicum Breuiarium, quo summam quattuor Mathematicarum adolescentes primum cognoscant (Compêndio de Matemática de [Michael] Psellus, para ensinar aos jovens as principais noções das quatro ciências matemáticas [aritmética, geometria, astronomia e música]). Na verdade, a primeira tradução para latim daquela obra grega do séc. XI parece ser a de Elias Vinet, cujo prefácio é de 1553, embora haja notícia de uma outra, datada de 1556, que desconhece a primeira. Estas obras não podiam fazer parte do programa de Matemática de Coimbra, mas constituem um indício da actividade de Elias Vinet no colégio. 
Curso quotidiano extraordinário, que teria sido facultativo, "destinado nomeadamente àqueles alunos que se preparavam para passarem à Teologia”. Nem havia razão para renunciar aos desígnios do Rei, que atribuía à cátedra um professor próprio. «Assim» escreve, «o aluno do Colégio das Artes, ao terminar o seu curso de Latinidade, com justiça poderia, se tal fora costume, acrescentar ao seu nome o título honorífico, tão prezado no Renascimento, de trium linguarum peritus.» (Ibidem)

Ocioso seria desenvolver aqui a discussão das fronteiras entre ensino secundário e superior, a aplicar ao novo ensino ministrado pelo Colégio. Se o estudo da gramática começava com as primeiras letras, o estudo da Retórica tornar-se-ia o coroar dos estudos literários. Em tudo o mais, o Colégio das Artes funcionava como uma Faculdade de Artes (incluindo a prestação de exames), salvo num único aspecto: exercerem os regentes a sua docência livres da tutela da Universidade, sujeitos apenas à autoridade do Principal do Colégio. ${ }^{11}$

O traço mais marcante do plano de estudos da Schola Aquitanica, o qual terá servido de modelo ao Colégio de Mestre André, é a visível afeição pelos estudos literários, em detrimento da atenção dada, pelo menos no breve parágrafo do documento, ao estudo da filosofia. É manifesta a vontade de aprofundar a língua, a latina e a materna, escrita e falada. É manifesto o desígnio de conviver assídua e directamente com os autores latinos, nos diversos géneros literários. É manifesta a eleição de Cícero acima de todos, mas ainda há lugar para Tito Lívio, Séneca e Quintiliano, Eutrópio, Pompónio Mela e Justino Mártir, e também para os próprios poetas, Terêncio, Ovídio, Virgílio, Horácio, Lucano e Séneca. Tudo isso, ao longo de um percurso cuidadosamente organizado em dez níveis, e minuciosamente explanado no programa de cada uma das classes. Se as dez classes (ou ordines) preenchem um só ciclo de estudos designado gramática, isso não quer dizer que não haja consciência das fronteiras entre aquele saber e o saber próprio da

${ }^{11}$ Com a fundação do Colégio das Artes, a Faculdade de Artes não desaparece. Subsiste ao lado das Faculdades de Teologia, Cânones, Leis e Medicina, não como corpo docente mas como congregação dos Mestres em Artes, tomando os seus membros parte nos Conselhos e préstitos universitários. A sua missão, porém, resumia-se a examinar e dar graus aos estudantes artistas (Brandão, 1924: 286). 
retórica. Com efeito, o autor desta Ratio define como retórica o objecto de estudo das quatro classes superiores de gramática, às quais se seguia o curso de Artes.

Assim, o que encontramos sob a designação de Gramática é afinal um programa de estudos que inclui a oratória, a retórica, a poética e a poesia, o teatro e a epistolografia, a historiografia e a geografia, a filosofia moral e política. E o que era isso, na língua de Cícero, senão as artes liberales ou optimae artes? Na língua de André de Gouveia, eram afinal as litterae humaniorum, que faziam daquela escola um gymnasium humaniorum litterarum (Ferreira 1944: 255).

\subsection{Uma respublica litteraria}

Por examinar fica a oração inaugural do Colégio das Artes pronunciada por Arnaldo Fabrício (1548), De Liberalium artium studiis oratio, mas ela só pode confirmar o mesmo favor dado às artes e às letras, saberes que designa como optimae artes (§78), litterae bonae (\$81), e ainda praestantissima doctrinae ac humanitatis studia (\$81). Respublica litteraria é o título que Fabrício confere à instituição inaugurada por André de Gouveia. No entanto, ao fazer o elogio das letras cultivadas naquela respublica litteraria, Fabrício não se refere apenas às bonae litterae, mas antes à humanitas litterarum (\$79), isto é, uma 'cultura humanística' (mais do que uma 'cultura literária') que segundo ele, crescera por obra de André de Gouveia, ao abrigo do Colégio de Guiena e haveria de crescer em Coimbra, ao abrigo do Colégio das Artes. Dir-se-ia que Arnaldo Fabrício se inspirara em Cícero para, como ele, fazer o memo elogio das letras, das suas qualidades como alimento individual para cultivo espírito, da sua utilidade social e colectiva.

Não admira portanto que, no último documento sujeito a exame, encontremos precisamente o Pro Archia de Cícero como objecto de estudo do programa de Primeira classe. Trata-se de uma carta que descreve os programas de estudo em vigor alguns anos depois da abertura do Colégio, em 1555, exactamente antes da entrega do Colégio das Artes à Companhia de Jesus. A descrição é feita pelo Padre Leão Henriques SJ, futuro reitor do Colégio de Coimbra e provincial da Companhia de Jesus em Portugal (1565-1570), que em 4 de Março de 
1555 envia (ignoro para que destinatário) informações sobre o estado em que se encontrava o Collegio del Rey (Lukács S.I. 1965: 644-645.) ${ }^{12}$

Após as já costumadas brevíssimas palavras dedicadas ao curso de Filosofia, em que se notifica a presença de Diogo Contreiras, Manuel de Pina e António de Souto, o autor da carta descreve as matérias dadas nas classes de Humanidades e Gramática. À cabeça, na classe de Prima e Secunda, encontra-se la oración de Cícero Pro Archia poeta, como que a coroar os estudos de Retórica, seguida de outros textos de Cícero, as Partitiones Oratoriae, o primeiro livro do De Inuentione e as Catilinárias. De resto, não há grandes alterações em relação ao programa inicialmente estabelecido por André de Gouveia: lá estão os Dísticos de Catão (porém, sem os Dicta de Erasmo), as comédias de Terêncio (Andria, Heautontimorumenos e Adelphi), as Epistolae de Cícero (Ad Familiares, Ad Atticum) e também os poetas, Virgílio (Eneida) e Ovídio (Epistolae e Tristia) ${ }^{13}$.

\section{Conclusões}

Se as litterae humaniores ou artes humaniores do Colégio das Artes designavam disciplinas como a gramática, a retórica, a filosofia, a poesia e a história, hoje essas disciplinas correspondem a um conjunto de artes e de saberes que compreendem, além da história e da filosofia, os estudos linguísticos e literários, assim como todos os saberes pertencentes à cultura humanística, incluindo, porque não, a música e as expressões artísticas que, como aqueles estudos, iluminam a Verdade sobre o homem e estão ao serviço da realização da pessoa humana.

Em 2007 a Universidade de Coimbra converteu o seu antigo Colégio das Artes numa nova Unidade Orgânica, vocacionada para a investigação e os estudos avançados em artes, não já as artes liberais mas as belas-artes, ignorando, aparentemente, a polissemia das palavras e a sua propriedade. E assim o edifício do antigo Real Colégio das Artes e Humanidades

${ }^{12} \mathrm{~A}$ carta em que D. João III comunica a Diogo de Teive que entregue o Colégio à Companhia tem a data de 10 de Setembro.

${ }^{13}$ Aos livros de Despautério para o estudo da gramática, sucedeu porém a Ars Antonii, isto é as Introductiones Latinae de António Nebrija. 
rompeu uma vez mais com as artes e as humanidades que lhe deram o ser.

É, pois, oportuno recordar que, do ponto de vista cultural, intelectual e institucional, a Faculdade de Letras é hoje a instituição que naturalmente sucede ao Colégio das Artes. O capital simbólico daquela primeira respublica litteraria constitui património imaterial da Faculdade de Letras. Poderemos nós alienar esse património, sem prejuízo das artes humaniores que professamos?

A celebração do primeiro centenário da actual Faculdade de Letras é ocasião oportuna para reflectir sobre a sua identidade matricial e, a essa luz, programar o seu futuro, qualquer que ele seja. Diante da necessidade actual de redescobrir a unidade do saber de que falava Cícero, a Universidade é ainda a instituição de quem se espera que conserve sempre o seu carácter de uniuersitas, onde as disciplinas se reconheçam, cada uma a seu modo, como partes de um todo. Ao alienar o seu Colégio das Artes, a Faculdade de Letras não estará a ser conivente com a fragmentação de saberes que secundariza quotidianamente as Humanidades? Ao invés de romper as fronteiras que separam as artes e as ciências, não estaremos nós, em nome da própria interdisciplinaridade, a impor novas fronteiras, circunscrevendo territórios e autoridade?

Nos diplomas com que confere os seus graus académicos, a Faculdade de Letras continua a autodesignar-se Liberalium Artium Facultas. É que, na realidade, nem as mudanças de paradigma se alcançam por decisão discricionária, nem o actual Colégio das Artes pode suprimir da sua memória a riqueza simbólica do nome que carrega.

\section{Bibliografia}

Américo Costa Ramalho (1998), Para a História do Humanismo em Portugal, vol. III. Lisboa, Imprensa Nacional Casa da Moeda.

Arnaldo Fabrício (1548) De Liberalium Artium studiis oratio Conimbricae habita in Gymnasio regio pridie quam ludus aperiretur. Conimbricae. Apud Ioannem Barrerium et Ioannem Alvarez.

Artur Moreira de Sá ed. (1966), Chartularium Uniuersitatis Portugalensis (1288-1537). I. Lisboa, Centro de Estudos de Psicologia e de 
Historia da Filosofia anexo à Faculdade de Letras da Universidade de Lisboa.

Carlos Alberto Louro da Fonseca (1974), "Defesa de Árquias" Introdução, tradução e notas in Cícero, As Catilinárias. Defesa de Murena. Defesa de Árquias. Defesa de Milão. Lisboa, Verbo, 171-181; 183-196; 293-300.

Francisco Leitão Ferreira (1944), Notícias Chronológicas da Universidade de Coimbra. Vol. III, Tomo I (1548-1551). Coimbra, Universidade

Henry de Vocht (1958), Les Débuts du Collège Trilingue de Louvain, 1517-1550, Uystpruyst, Lovanii.

Ladislaus Lukács S.I. ed. (1965), Monumenta Paedagogica Societatis Iesu, Vol. I 1540-1556, Roma, Monumenta Historica Societatis Iesu.

Margarida Miranda (2009), Código Pedagógico dos Jesuítas. Ratio Studiorum da Companhia de Jesus - Regime escolar e Curriculum de estudos. Edição bilingue latim-português. Versão portuguesa de Margarida Miranda. «Ratio Studiorum, um modelo pedagógico» por José Manuel Martins Lopes S.J., Lisboa, Esfera do Caos [= Ratio Studiorum].

Maria Cândida Monteiro Pacheco (1997) «Triuium e quadriuium», in AA.VV. História da Universidade em Portugal, vol. I, tomo 1 (1290-1536), Coimbra, UC-FCG: 155-177.

Maria José Pacheco (1959), A Oração Inaugural do Colégio das Artes de Arnaldo Fabrício. Faculdade de Letras da Universidade de Coimbra [Dissertação policopiada].

Mário Brandão (1924), O Colégio das Artes. I. 1547-1555. Coimbra, Imprensa da Universidade.

Olga Weijers e Louis Holtz eds. (1997), L'Enseignement des disciplines à la Faculté des arts. Paris et Oxford, XIII ${ }^{e}-X v^{e}$ siècles. Brepols.

Paul O. Kristeller (1995), Tradição clássica e pensamento do Renascimento, Lisboa, Edições 70, maxime "O movimento humanístico": 11-29 [Original: The Classics and the Renaissance Thought, Harvard University Press]. 